\title{
Increase in domestic electricity consumption from particulate air pollution
}

\author{
Pan He $\oplus^{1,2,6 \bowtie, ~ J i n g ~ L i a n g ~}{ }^{3,6}$, Yueming (Lucy) Qiu $\oplus^{3,6} \bowtie$, Qingran Li ${ }^{4}$ and Bo Xing ${ }^{5}$
}

\begin{abstract}
Accurate assessment of environmental externalities of particulate air pollution is crucial to the design and evaluation of environmental policies. Current evaluations mainly focus on direct damages resulting from exposure, missing indirect co-damages that occur through interactions among the externalities, human behaviours and technologies. Our study provides an empirical assessment of such co-damages using customer-level daily and hourly electricity data of a large sample of residential and commercial consumers in Arizona, United States. We use an instrumental variable panel regression approach and find that particulate matter air pollution increases electricity consumption in residential buildings as well as in retail and recreation service industries. Air pollution also reduces the actual electricity generated by distributed-solar panels. Lower-income and minority ethnic groups are disproportionally impacted by air pollution and pay higher electricity bills associated with pollution avoidance, stressing the importance of incorporating the consideration of environmental justice in energy policy-making.
\end{abstract}

A ir pollution has resulted in many types of negative externalities, a situation that calls for policy intervention to address the associated damages. Policymakers and research are widely concerned with increases in mortality risk, which are direct damages induced by pollution, as well as co-damages in terms of other welfare losses. These damages are generated via different channels including the physical and mental health impact on human beings, decreases in labour productivity ${ }^{1,2}$, the decline in subjective well-being ${ }^{3}$, the harm of cognitive competence ${ }^{4,5}$, disturbances in ecosystem health ${ }^{6}$, a diminished value of local environmental amenities and properties ${ }^{7}$, increases in household medical expenditure and so on. Accurate assessment of such externalities is crucial to estimating the social cost of pollution for the design and evaluation of policies such as a Pigouvian tax imposed on polluters for such external costs or for pollution control, or a cap-and-trade programme that establishes a market issuing allowances to internalize such $\operatorname{cost}^{8}$. While direct pollution damages are often measured in existing studies, there are not many discussions in the literature about the magnitude of the co-damages. A key challenge to quantify these co-damages, however, is to understand the interactions among pollution, human behaviours ${ }^{9}$ and technologies. People can mitigate exposure to environmental risks by taking various avoidance behaviours, such as adjusting outdoor activities ${ }^{10,11}$ and purchasing face masks and air purification systems in the short term ${ }^{9,12}$, and migrating to new living locations in the longer term ${ }^{13}$. Avoidance behaviours alleviate the negative health impact of pollution ${ }^{14}$ but come at a cost, for example, spending less time doing outdoor activities ${ }^{10,15}$, and may lead to further impacts such as increased energy consumption due to a shift from natural to mechanical ventilation ${ }^{16}$, and increased need for heating or air-conditioning or for other activities such as watching television ${ }^{17,18}$ in residential buildings. Commercial buildings may also be affected via further complexities if individuals choose to work remotely due to air pollution to avoid exposure during commuting ${ }^{19}$. However, commercial buildings might have better indoor air quality due to better ventilation ${ }^{20}$ so that people can stay in commercial buildings for longer period of time. These two effects can cancel out, and thus we hypothesize that air pollution does not have a statistically significant impact on commercial buildings as a whole. Such effects and the consequential extra environmental damage are, however, hardly addressed explicitly and quantitatively in current studies, which leads to biases in damage evaluation. Our paper fills in this gap in the literature.

While electricity demand is driven up by pollution-averting behaviours, air pollution can also reduce electricity supply. High concentrations of particulate matter reduce solar electricity generation due to the changed solar irradiance. The emission of aerosols can attenuate solar radiation by scattering and absorbing sunlight before it reaches the solar panel${ }^{21}$, and thus reduces photovoltaic (PV) performance ${ }^{22,23}$. Large particles in particulate matter can also generate dust on top of solar panels. In areas with severe air pollution such as China, the potential of solar PV generation decreased on average by 11-15\% between 1960 and 2015 (ref. ${ }^{22}$ ); the decrease of point-of-array irradiance can even reach $35 \%$ in the most polluted area $^{23}$. Such interaction adds another dimension to the complexity of assessing pollution externalities. Existing studies take a predominantly engineering perspective that relies on computer simulations to calculate the change in solar irradiance due to air pollution or on field experiments to measure the changes in electricity generation of a few solar panels in response to air pollution. While providing critical estimation on the relationship between particulate pollution and solar electricity generation in certain refined meteorological and geographical conditions, these studies fall short in evaluating how much actual solar generation is affected at a large scale. Our paper contributes on empirical grounds and serves as a crucial reference for policy-making.

As pollution co-damages are closely related to both demand-side human behaviours and supply-side solar power generation, the distribution of these co-damages raises environmental justice concerns. Lower-income households or minority ethnic groups can be more vulnerable to the impact of air pollution. Individuals from

'Department of Earth System Science, Institute for Global Change Studies, Tsinghua University, Beijing, People's Republic of China. ${ }^{2}$ School of Earth and Ocean Sciences, Cardiff University, Cardiff, UK. ${ }^{3}$ School of Public Policy, University of Maryland, College Park, MD, USA. ${ }^{4}$ Nicholas School of the Environment, Duke University, Durham, NC, USA. ${ }^{5}$ Department of Forecasting, Resource Planning and Development, Salt River Project, Tempe, AZ, USA. ${ }^{6}$ These authors contributed equally: Pan He, Jing Liang, Yueming (Lucy) Qiu. e-mail: hepannju@gmail.com; Yqiu16@umd.edu 
Table 1 | Effect of air pollution on electricity consumption in residential buildings

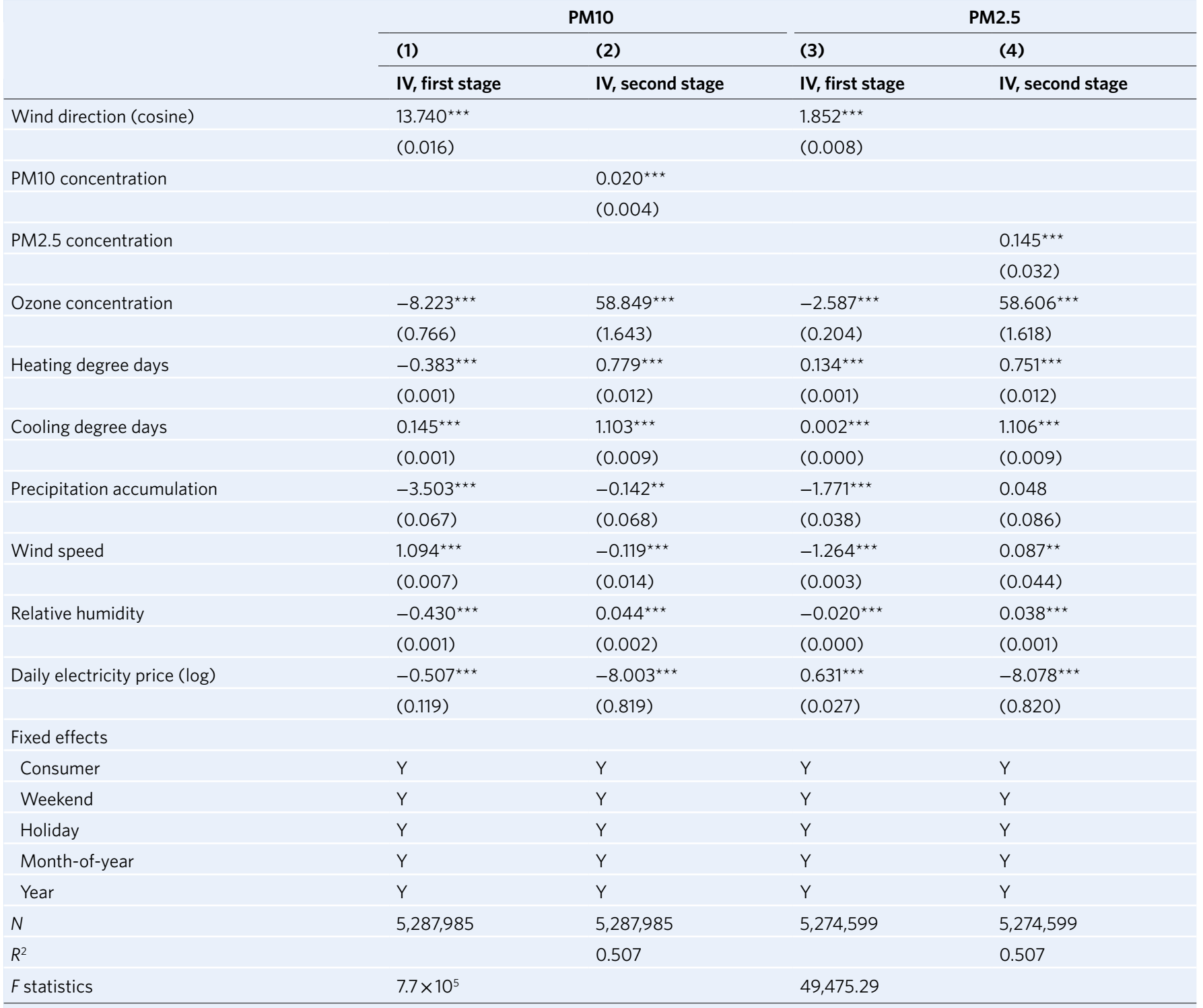

Notes: Standard errors in parentheses are clustered to building unit level. ${ }^{\star} P<0.1,{ }^{\star \star} P<0.05,{ }^{\star \star \star} P<0.01$. N denotes the sample size and $R^{2}$ denotes the goodness-of-fit of the regressions.

these groups usually reside in locations with higher air pollution levels ${ }^{24}$. Moreover, they may live in affordable housing and buildings that are old, not well insulated and equipped with fewer energy-efficient appliances, all of which leads to higher energy-related expenditures ${ }^{25,26}$. Increased electricity bills due to more indoor hours, therefore, translates into a larger proportion of the household income for these groups, compared to their higher-income or non-minority counterparts. This constrains other essential expenditures such as on medical services by these lower-income and minority households, thus leading to further adverse health impacts ${ }^{27}$. Our analyses incorporate the equity aspects of pollution co-damages to provide necessary implications for policy design towards environmental justice.

This article demonstrates how the interactions among air pollution, human defensive behaviour and the energy supply system can influence the estimates of negative externalities caused by air pollution. Using consumer-level daily and hourly electricity consumption data and solar panel generation records in the city of Phoenix, Arizona, during the period 2013-2018, we show how particulate air pollution, indicated by concentrations of both PM10 and PM2.5 (that is, particulate matter 10 micrometres or less in diameter, and 2.5 micrometres or less, respectively), triggers consumer avoidance behaviours as well as lowers the generation of solar energy. Our sample covers 4,313 residential buildings and 17,422 commercial buildings. A variety of demographic and socio-economic characteristics are associated with the consumer dataset, based on which we further explore the heterogeneity of the co-damages associated with income and ethnicity. Estimates can be biased by endogeneity issues due to reverse causality (that is, air pollution induces changes in energy consumption as well as solar electricity generation, which in turn also affects the air quality) and missing variables (for example, unobservable characteristics of the local economy and physical environment can affect the air quality and energy consumption simultaneously). To address the endogenous biases, we use wind direction as an instrumental variable (IV) for pollution concentration. This IV has a direct impact on concentrations of pollutants but not on energy consumption, which creates variation in air quality that is exogenous to consumption, thus leading to an 


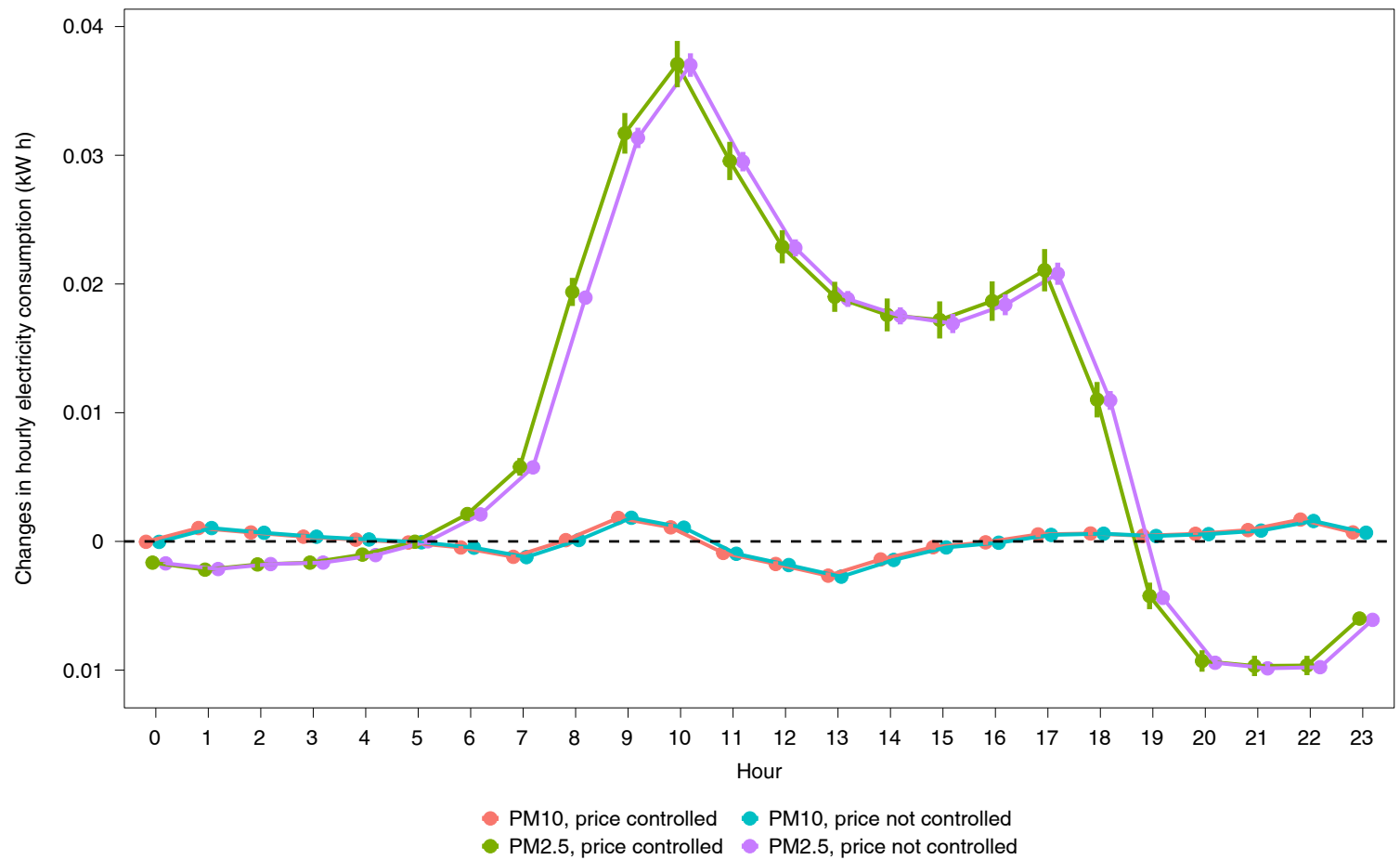

Fig. 1 | Change in residential hourly electricity consumption due to one-unit increase in air pollution concentration. The coloured dots show the changes in hourly electricity consumption, obtained from panel regression at the hourly level. The coloured vertical lines show the $95 \%$ confidence intervals. As the information on hourly electricity price is available only for a small part of the residential and commercial samples, we conduct the analysis both with and without the regressor of price as a control variable.

unbiased estimation of the pollutant coefficient. Our main results are based on daily average data. We also analyse hourly data to examine the intra-day heterogeneity in the impact on electricity usage. The study area of our analysis is the fifth-most populated city in the United States ${ }^{28}$ and ranks among the top five most-polluted cities in the country ${ }^{29}$. This suggests that, even though they are based on a region of a developed country, our results can provide valuable insights and benchmark statistics when compared with studies in developing countries, with dense populations and low-ranked air quality.

\section{Effect of air pollution on the demand sectors}

Through an IV fixed-effects panel regression, we regress the individual household's daily electricity consumption on air pollution level, while controlling for other confounding variables. Detailed modelling can be found in the Methods section. The validity of the IV estimation is also supported by the first-stage regression, which shows a significant positive correlation between the daily average cosine of the prevailing hourly wind direction angle and the concentration of air pollution, meaning that wind in the upwind direction of pollution sources would bring higher particulate concentration (columns 1 and 3 in Table 1 ). The considerable $F$ statistics of far more than ten for testing the statistical significance of the excluded instrument indicate a strong IV in both the regressions for PM10 and PM2.5. We find that a higher concentration of particulate pollutant results in a statistically significant increase in residential electricity consumption. An increase of $1 \mu \mathrm{g} \mathrm{m}^{-3}$ in PM10 concentration raises the daily residential electricity consumption by $0.020 \mathrm{kWh}$ (column 2 in Table 1). Residents are more sensitive to a change in PM2.5 concentration, as a $1 \mu \mathrm{g} \mathrm{m}^{-3}$ rise in PM2.5 concentration causes an $0.145 \mathrm{kWh}$ (column 4 in Table 1) increase in daily electricity consumption. In this way, one more standard deviation of PM10 and PM2.5 would increase the daily residential electricity consumption by $0.85 \%$ and $1.74 \%$, respectively, from the mean, based on the descriptive statistics in Supplementary Table 1. Such effects are also seasonally heterogeneous (Supplementary Table 12) as the increased electricity consumption has a larger magnitude in the peak of summer (July and August), while the significance diminishes during the winter (November to April).

To validate our hypothesis that the increased electricity consumption is caused by averting behaviours that shift outdoor activities indoors, we next examine the pollution-kilowatt-hour relationship on an hourly basis. Results using hourly data confirm that air pollution increases residential electricity consumption and imply a possible reallocation of time due to air pollution. As shown in Fig. 1, residential electricity consumption increases considerably during the daytime but decreases slightly during evenings when affected by air pollution. While both are statistically significant, the summed change (the area above the horizontal line of zero minus the area below) still shows an overall increase of daily electricity consumption aligning with the findings based on Table 1 . This possibly indicates a change of activities during the day: as air quality deteriorates, residents tend to participate in indoor energy-dependent activities such as watching television and turning on the heating or cooling system. They may also move activities usually conducted in the evenings, for example, doing the laundry, ahead to the daytime, so electricity consumption during the night-time drops. The drop in consumption during the evening might also be due to the effect of pre-cooling or pre-heating, from turning on the heating or cooling system during the daytime.

To further support our findings, we test whether individuals tend to reduce outdoor trips, using a daily county-level dataset of mobility nationwide in the United States (details are included in the Methods). As shown in Supplementary Table 13, the number of trips per person decreases as the concentration of air pollution increases, implying that people are staying home for more hours due to air pollution. 


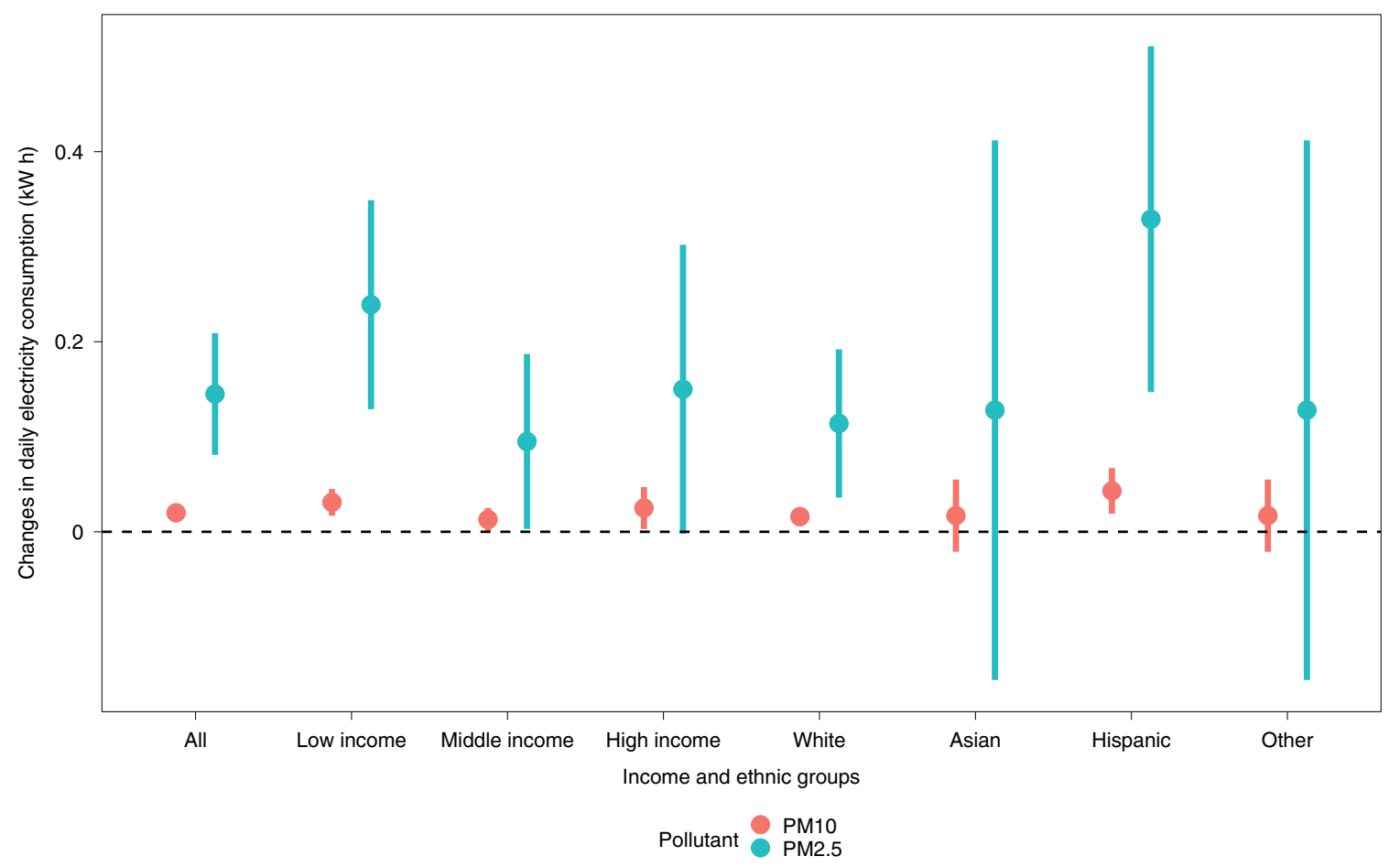

Fig. 2 | Change in daily residential electricity consumption due to one-unit increase in air pollution concentration. Results are based on IV methods. The solid dots represent the values of the coefficients that measure the change in daily electricity consumption in response to a $1 \mu \mathrm{g} \mathrm{m} \mathrm{m}^{-3}$ increase in $\mathrm{PM}$ concentration. The vertical lines represent $95 \%$ confidence intervals.

We next discern the effects of air pollution among residential consumers with different socio-economic characteristics. The potential heterogeneous effects can be caused by different aspects of environmental injustice. On the one hand, as consumers of disadvantaged socio-economic status can be exposed to higher levels of pollution ${ }^{8}$ and can live in houses that are less energy efficient ${ }^{25,26}$, their pollution-induced increase in electricity demand can be larger than that of their advantaged counterparts. On the other hand, their ability to self-protect against air pollution is likely to be restricted by their limited disposable income, or they may be simply less attentive to air pollution. If the effect of these constraints dominates their behavioural responses to pollution, then we may observe a smaller change in electricity demand for disadvantaged households. As a result, whether and how the effect of air pollution on electricity consumption differs across socio-economic status becomes an empirical question. Our summary statistics show that lower-income and non-white consumers are associated with higher particulate matter $(\mathrm{PM})$ concentrations and lower baseline electricity consumption (Supplementary Table 2), implying a possible heterogeneous effect. Thus, we test such heterogeneity for different income and ethnic groups. Using the available data on household characteristics, the sample is divided into three levels of per capita income: low, medium and high (see Methods for details). The sample is also divided into four ethnic groups (White, Asian, Hispanic and other) to conduct the regression analysis separately.

The results show that lower-income and Hispanic consumers have a larger increase in electricity consumption in response to a unit increase in PM pollution. The IV estimates in Fig. 2 illustrate that the marginal effect of pollution on electricity demand is the highest for the low-income group. For ethnic groups, Hispanic consumers increase their electricity consumption more than white consumers. The empirical estimates for heterogeneous groups imply that the effect of low energy efficiency and high exposure possibly overrides the constraint of disposable income. By contrast, a previous study found that higher-income consumers need to use more energy in response to changing weather conditions in China ${ }^{30}$. Existing studies have found that lower-income consumers tend to live in homes that are not energy efficient ${ }^{25,26}$, which can lead to a higher increase in electricity consumption due to air pollution. Two studies ${ }^{31,32}$ find that Hispanic households have higher energy use intensity due to residing in less energy-efficient homes. These findings of Hispanic households help justify our results because when air pollution increases and people need to spend more time indoors, inefficient homes (such as Hispanic homes) will increase their electricity consumption more compared to an efficient home. The medium-income group shows less of an electricity increase compared to both the low-income and high-income groups, which might result from low-income households having inefficient homes $^{25,26}$ and high-income households needing more energy in response to changing weather condition $s^{30}$. The socio-economic heterogeneity embedded in air pollution issues requires more subtle investigations and tests given the multiple mechanisms that can balance the effects of each other. We also reran the model separately for each residential building to get the unique estimated impact for the individual consumer. The results show similar heterogeneity. As shown in Supplementary Fig. 1, air pollution demonstrates a different marginal effect for each building, and the summary statistics in Supplementary Table 5 show a similar pattern as that observed in Fig. 2.

Our results show that contrary to findings in the residential sector, electricity usage in commercial buildings as a whole sample is not significantly affected by air pollution in general, although the usage in individual industries shows statistically significant changes. The results in Table 2 show that although the IV is still valid and strong (the coefficients of Wind cosine are positively significant in the first-stage results in columns 1 and 3 , and the $F$ statistics are considerable), IV estimates indicate no statistically significant effects (columns 2 and 4 in Table 2). In this way, the hypothesis that particulate pollution has no effect on energy use in commercial buildings as a whole cannot be rejected. We then examine if the hourly 
Table 2 | Effect of air pollution on electricity consumption in commercial buildings

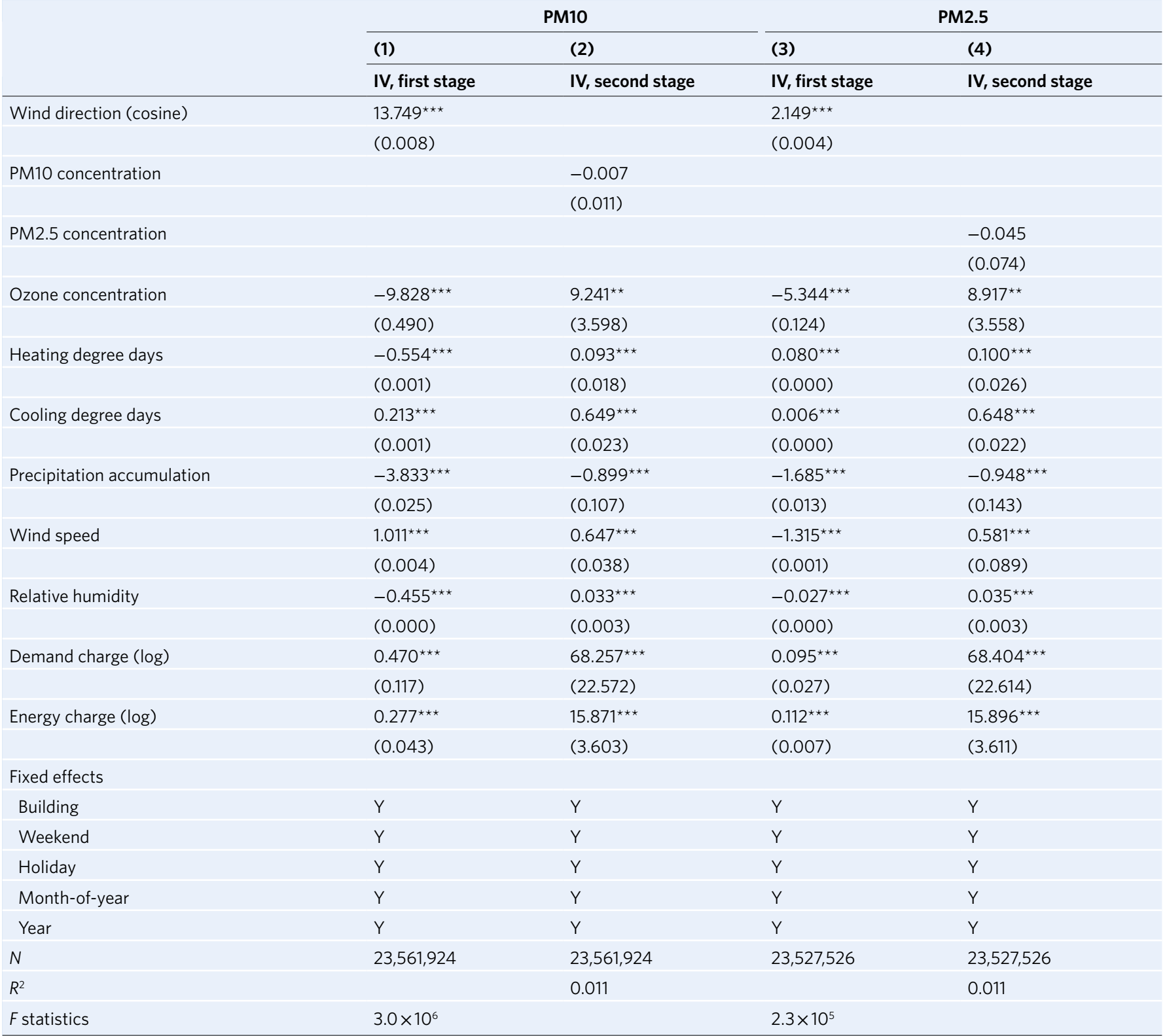

Notes: Standard errors in parentheses are clustered to building unit level. ${ }^{\star} P<0.1,{ }^{\star \star} P<0.05,{ }^{\star \star \star} P<0.01$. $N$ denotes the sample size and $R^{2}$ denotes the goodness- of-fit of the regressions. The demand charge and energy price are calculated by taking the average of the marginal prices of a price plan in a given month. Thus, the coefficients for the prices measure the differences in electricity consumption of consumers across different price plans across different months. Some large electricity-using consumers were on price plans that have lower prices.

estimates could imply any indoor-outdoor activity shifts. There is not sufficient evidence to show that air pollution affects electricity usage in commercial buildings (Fig. 3). Although the results show a similar pattern of electricity consumption in commercial buildings as in residential buildings, the coefficients of hourly pollution concentrations are barely statistically significant.

Such an insignificant effect on commercial buildings overall is likely a result of mixed effects by air pollution that cancel each other out. On one hand, when estimating the micro-environment exposure, incorporating work activities will induce higher exposure to air pollution compared to home-only activities, partially due to higher pollution exposure during transit or commuting ${ }^{19}$. This implies that workers have the incentive to stay at home or to work from home to avoid a higher average pollution exposure, which lowers the energy consumption of the commercial buildings. We further test this hypothesis by our analysis of the effect of air pollution on personal trips. With a daily county-level dataset of mobility nationwide in the United States, we test whether individuals tend to reduce outdoor trips (details are included in the Methods). As shown in Supplementary Table 13, the number of trips per person decreases as the concentration of air pollution increases. The same conclusion holds for both work trips (Supplementary Table 14) and non-work trips (Supplementary Table 15). On the other hand, commercial buildings on average might have a different building envelope or better building management system ${ }^{20}$ that can lead to a better indoor environment ${ }^{33}$ compared to residential buildings, so that when ambient air pollution increases, some people might want to stay inside commercial buildings for a longer period time, potentially increasing electricity in these buildings. Building occupants may also use less natural ventilation in polluted weather, and thus can increase the energy consumption of buildings due to increased mechanical ventilation ${ }^{16}$. These effects may cancel out so that we 


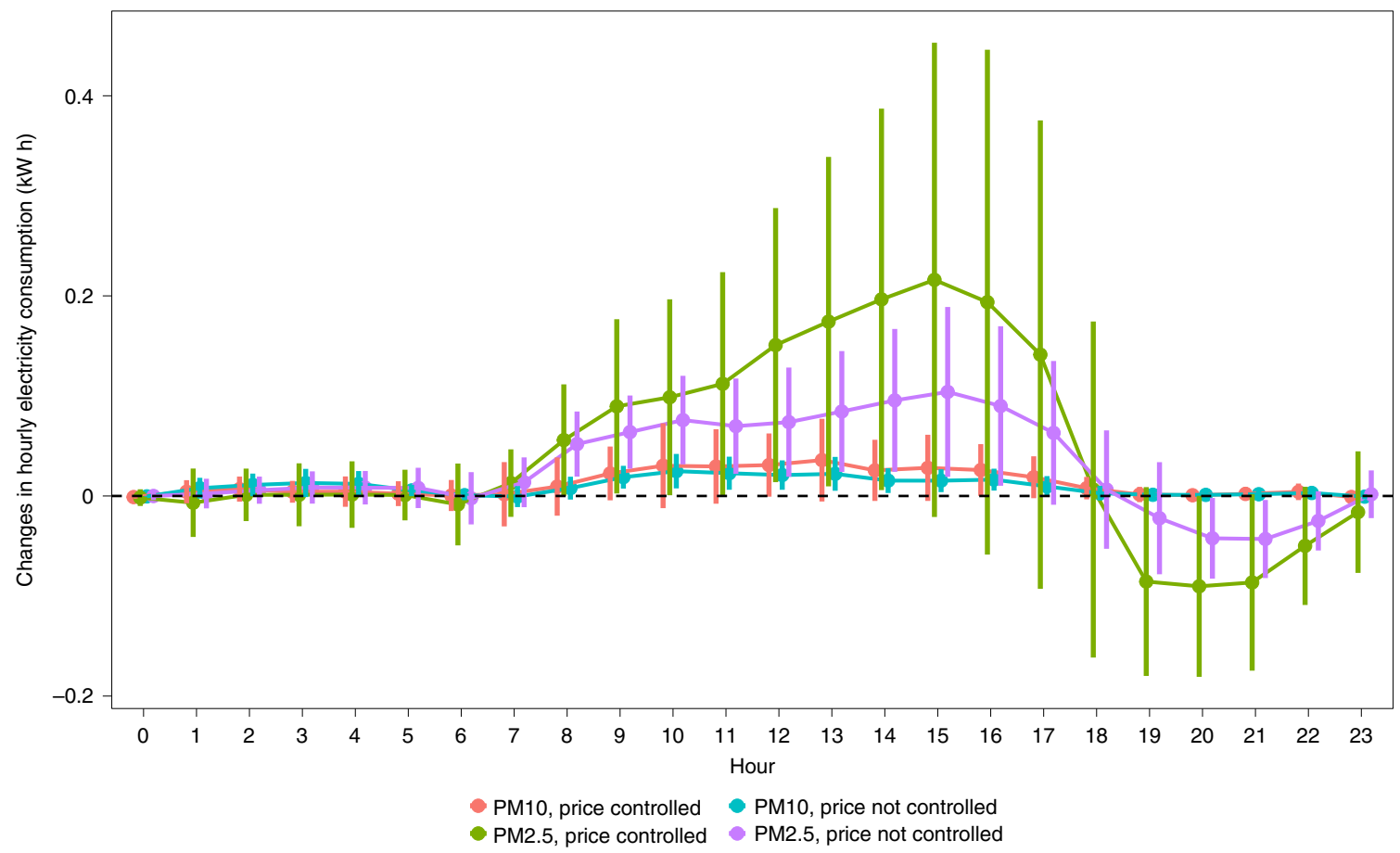

Fig. 3 | Change in commercial hourly electricity consumption due to one-unit increase in air pollution. The coloured dots show the changes in hourly electricity consumption, obtained from panel regression at the hourly level. The coloured vertical lines show the $95 \%$ confidence intervals.

are not observing a statistically significant effect of air pollution on average for all commercial buildings in our sample.

The insignificant effect of air pollution on commercial buildings as a whole actually validates our residential electricity consumption result. There could be a concern that our regression model still fails to capture some physical relationship between electricity consumption and other unmeasured meteorological variables, which correlates with air pollution. Or there could be a concern about an incorrectly specified functional form (an incorrect description of the relationship between our independent and dependent variables). As a result, the positive impact of air pollution on residential electricity consumption could be purely due to these physical relationships, and not due to consumer behavioural change. The insignificant result in the commercial sector actually implies that our regression model can capture those physical relationships well, so that our estimated increase in residential electricity consumption is indeed due to consumers' behavioural changes.

Such statistically insignificant results of commercial buildings can, however, conceal the sectoral heterogeneity as air pollution can substantially affect the commercial sectors that are closely related to indoor activities. Due to the nature of different industries, each commercial building serves a specific purpose, with some sectors more likely to be affected by air pollution. Sectors such as retail trade, recreation and service can have increased electricity consumption where more of their customers spend more time inside the buildings to avoid being exposed to outdoor pollution. Thus, we separate the effect by sector as shown in Fig. 4. With a similar averaged pollution concentration across all sectors (Supplementary Table 4), the retail sector responds most intensely to an increase in air pollution concentration $(0.086 \mathrm{kWh}$ increase in electricity consumption per $\mu \mathrm{g} \mathrm{m}^{-3}$ increase of PM10 concentration, and $0.560 \mathrm{kWh}$ increase per $\mu \mathrm{g} \mathrm{m}^{-3}$ increase of PM2.5 concentration), followed by the recreation and service sector $\left(0.026 \mathrm{kWh}\right.$ per $\mu \mathrm{g} \mathrm{m}^{-3}$ and $0.167 \mathrm{kWh}$ per $\mu \mathrm{g} \mathrm{m}^{-3}$, respectively). By contrast, the other sectors reduce their electricity consumption, also as expected $\left(0.028 \mathrm{kWh}\right.$ per $\mu \mathrm{g} \mathrm{m}^{-3}$ and $0.178 \mathrm{kWh}$ per $\mu \mathrm{g} \mathrm{m}^{-3}$ for PM10 and PM2.5, respectively; both significant at a $90 \%$ confidence level). As a result, one standard deviation increase of PM10 and PM2.5 would lead to a $1.82 \%$ and $3.34 \%$ increase, respectively, in the retail trading sector; $1.13 \%$ and $2.00 \%$ increase, respectively, in the recreation and service sector; and $0.79 \%$ and $1.39 \%$ reduction, respectively, of electricity consumption in the other sectors. These effects with opposite directions in different sectors balance each other out when summed, and thus lead to an insignificant change in energy consumption for the whole sample. Taken together with our analysis above, these results show that individuals are more likely to reduce outdoor trips in general and particularly those related to work. However, the final destinations for the remaining trips may shift at least partially from open spaces to sheltered areas, and thus lead to more energy consumption in malls, recreation centres and so on. This distributional result stresses the importance of looking into sectoral nuance based on understandings of how consumer behaviours differ by industry as a response to varying air quality.

\section{Effect of air pollution on the supply sector}

We then used a similar panel IV regression to regress individual consumers' daily solar electricity generation on air pollution level, while controlling for confounding variables (Methods). The IV of wind direction again proves powerful in explaining the variation of PM10 and PM2.5 with its positive significance in columns 1 and 3 in both Tables 3 and 4 , while the $F$ statistics continue to verify it as strong. We find that particulate pollution also reduces the electricity generation of distributed-solar panels in both residential and commercial buildings. IV estimation shows that a $1 \mu \mathrm{g} \mathrm{m}^{-3}$ increase in PM10 concentration significantly reduces the electricity generated by solar panels by $0.435 \mathrm{kWh}$ in residential buildings (column 2 in Table 3) and by $0.022 \mathrm{kWh}$ in commercial buildings (column 2 in Table 4). PM2.5 has an even larger effect-a $1.888 \mathrm{kWh}$ reduction per $\mu \mathrm{g} \mathrm{m}^{-3}$ increase for residential buildings (column 4 in Table 3) and $0.093 \mathrm{kWh}$ reduction per $\mu \mathrm{g} \mathrm{m}^{-3}$ increase for commercial buildings (column 4 in Table 4 ). In terms of percentage change, one standard deviation increase of PM10 and PM2.5 would result in a 


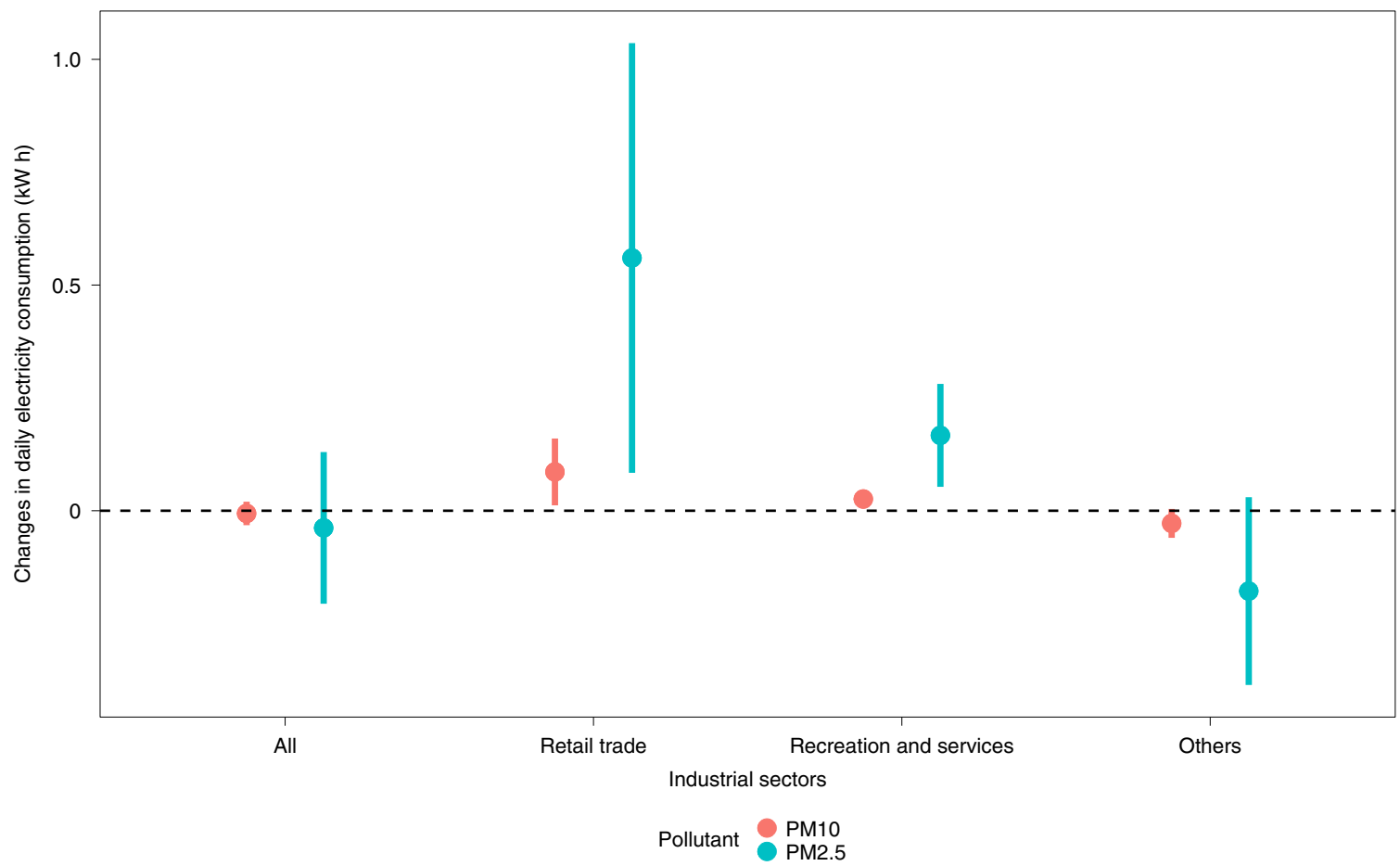

Fig. 4 | Change in daily commercial electricity consumption due to one-unit increase in air pollution. Results are based on IV methods. The solid dots represent the values of the coefficients that measure the change in daily electricity consumption in response to a $1 \mu \mathrm{m} \mathrm{m}^{-3}$ increase in PM concentration. The vertical lines represent $95 \%$ confidence intervals.

$25.01 \%$ and $30.64 \%$ reduction, respectively, of solar electricity generation for residential buildings with solar panels from the mean solar electricity generation, and $0.13 \%$ and $0.15 \%$ reduction, respectively, for commercial buildings. The comparison also indicates that commercial buildings are much less affected if considering that the power of solar panels is on average larger in commercial buildings, referring to the descriptive statistics in Supplementary Tables 1 and 3. A possible reason is that the solar panels in commercial buildings are better maintained, with dust cleaned off them in a timely manner.

\section{Discussion}

This study explores the co-damage of air quality degradation via human defensive behaviour on the demand side and the performance of clean energy techniques on the supply side, respectively. Our results show that particulate pollution, while exposing individuals to health risks with direct emissions, can further add to their loss with regenerative feedback, which boosts energy consumption due to longer times spent indoors and the downgraded performance of solar panels. While previous studies predominantly focus on the positive consequences of the defensive behaviours in alleviating health impacts ${ }^{10,12}$, this research shows the possible pathways in which air pollution generates extra damage by interacting with such defensive behaviours ${ }^{9}$. Our analysis also shows that residents from low-income or Hispanic groups are more heavily affected, highlighting the vulnerability of those of specific socio-economic status in responding to environmental change and the potential environmental justice issues that should be addressed by policy design ${ }^{24,27}$.

Several limitations should be noted. First, our analysis addresses the situation in the city of Phoenix, Arizona. In spite of its top rank for air pollution levels in US cities, the concentration of PM is still far less than that in many developing countries such as Mexico or China ${ }^{34,35}$. Meanwhile, response levels can also differ due to cultural differences. Therefore, our results should be extrapolated with caution. In addition, our dataset lacks information on specific household end-use activities (for example, heating and cooling, or air purification). Thus, we are not able to pinpoint exactly what appliance or appliances are more intensively used against higher particulate concentrations, for further details on the mechanisms that we discuss. We leave these for future research that draws on high-resolution data in various geographical areas.

Several critical policy implications stem from the findings of this research. First, when calculating the marginal damage factors from air pollution, policymakers need to explicitly consider the co-damages generated from the feedback of consumer behaviours and clean technology performance, which is insufficiently discussed in the current literature, as well as policy analysis and evaluation. Lack of consideration of these pollution co-damages will lead to an under-estimation of the welfare gains from pollution control policies. Our results also stress the necessity to investigate comprehensively the consequences of air quality alerting systems, for example, alleviated health risks ${ }^{36}$, changed automobile traffic flows as individuals endeavour to escape from pollution as a response ${ }^{37}$, decreased outdoor recreation ${ }^{10,38}$ and so on. Second, the fact that air pollution disproportionally affects those of low socio-economic status threatens energy and environmental justice, and again stresses that air pollution control can not only result in health benefits as a whole, but also contribute to an equitable distribution of such benefit. The disproportional impact also highlights the importance of energy policies that can improve the home energy efficiency of lower-income and ethnic minority groups to accelerate the achievement of fairness and equity. Third, our findings provide one more justification for the need to clean the electricity grid and improve the efficiency of renewable energy generation techniques. In addition, the expansion of solar power should consider the effect of air pollution when setting reasonable development targets. The results comparing the impacts on commercial PV units and residential PV units suggest that there should be clear messages or incentives to communicate the importance of the cleaning and maintenance of PV units to residential consumers. 
Table 3 | Effect of air pollution on solar energy generation in residential buildings

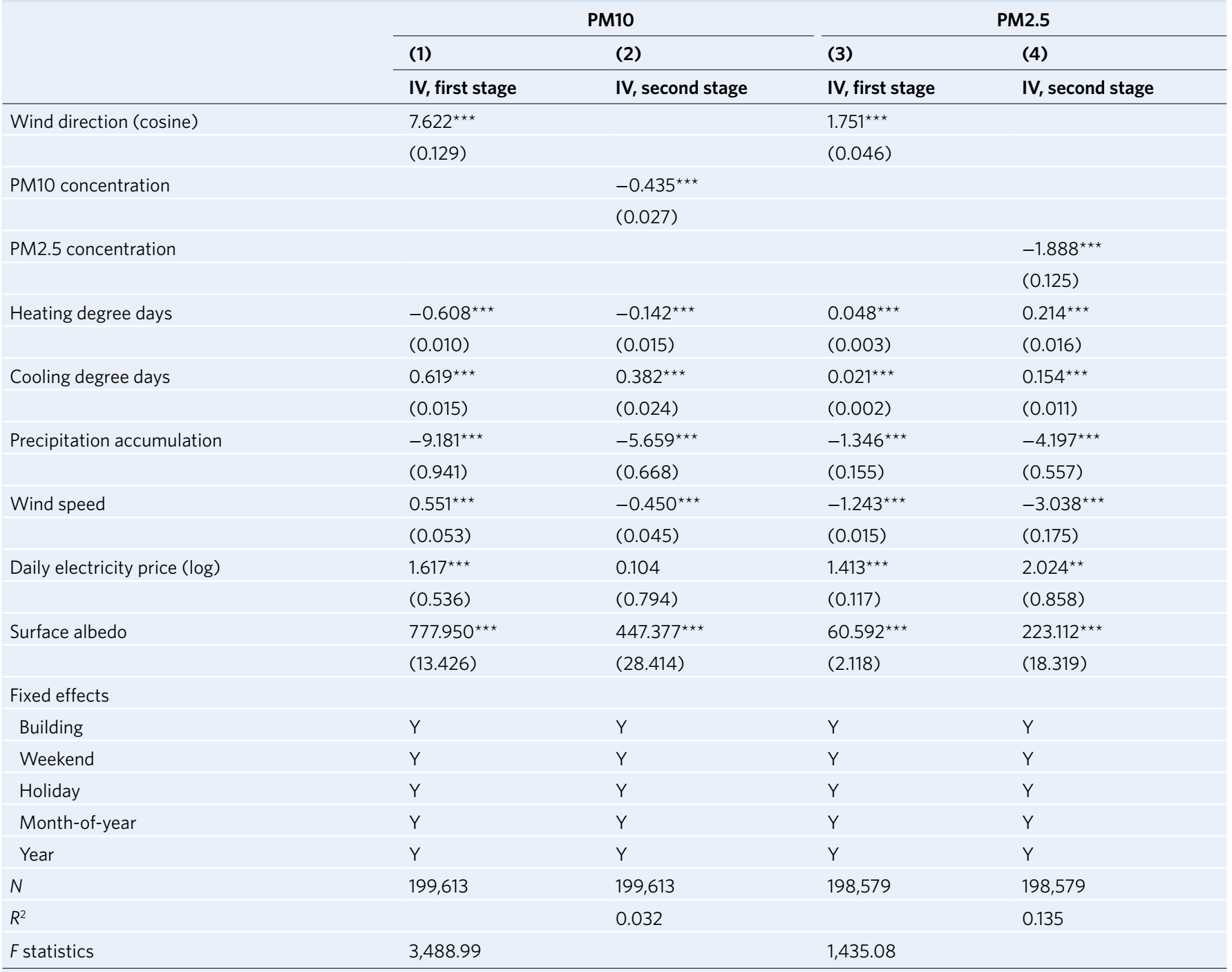

Notes: Standard errors in parentheses are clustered to building unit level. ${ }^{\star} P<0.1,{ }^{\star \star} P<0.05,{ }^{\star \star \star} P<0.01$. N denotes the sample size and $R^{2}$ denotes the goodness-of-fit of the regressions.

\section{Methods}

Data. The data were provided by Salt River Project, one of the two largest utility companies in Arizona. Hourly electricity consumption in kilowatt-hours was available for 4,313 residential units (spanning from May 2013 to April 2017) and 17,422 commercial units (spanning from May 2013 to April 2018). For the residential units in the sample, a Residential Equipment and Technology Survey was also conducted in 2014, which asked about detailed sociodemographic information, building characteristics, appliance and other energy technology attributes, and energy consumption behaviours. For the commercial units, a six-digit code in the North American Industry Classification System is available to identify the sector type of the building. We aggregate the electricity consumption to the daily level for analysis. The daily electricity price is constructed by taking the average of the hourly prices. For commercial consumers, both the electricity charge and demand charge are included as price variables. The zip code zone of each building is also available in the dataset, which enables a spatial match with the air quality and meteorological variables.

Salt River Project also has distributed-solar consumers in its service territory. These solar panels can be installed on the rooftop of buildings or can be ground-mounted. For each distributed-solar consumer, our dataset has information on the hourly electricity generated by the consumer's solar panels, along with the installation dates of the solar panels. There are 260 residential distributed-solar consumers (6.03\% of the residential sample) and 330 commercial distributed-solar consumers (1.89\% of the commercial sample) in our dataset.

We combine meteorological observations from multiple sources. Records of air quality, including daily average concentrations of PM2.5 and PM10, are retrieved from pre-generated data files of the United States Environmental Protection Agency ${ }^{39}$. Climate factors including the daily average temperature, total precipitation and average wind speed are obtained from Global Surface Summary of the Day ${ }^{40}$. The hourly wind direction data come from the Environmental Protection Agency's pre-generated data files. We obtain the solar irradiance data from the National Renewable Energy Laboratory's National Solar Radiation Database ${ }^{41}$. For missing solar irradiance data for a given location in a given time period, we use the simulated solar irradiance by the National Renewable Energy Laboratory for a given day in that location in a typical meteorological year.

We adopt an inverse distance weighting interpolation that has commonly been used in previous literature ${ }^{42,43}$ to match the air quality and meteorological records with the zip code zone of each building. First, the distance between each air quality monitoring station and the geometric centre of the zip code zone is calculated. Next, the daily records of all the stations less than $50 \mathrm{~km}$ away from the geometric centre are averaged together and weighted by their inversed distance to the centre. This weighted average is used as the matched air quality record for all the buildings within the zip code zone. The climate records are matched in a similar way. The inverse distance weighting is conducted in Stata 14.0 using the wtmean command with 34 meteorological stations and 67 air pollution monitoring stations. To test whether our analysis is sensitive to the radius of the inverse distance weighting procedure, we change the caliper to $10 \mathrm{~km}$ and $20 \mathrm{~km}$ and rerun the analysis, as shown in Supplementary Tables 16-19 (for 10 km) and Supplementary Tables 2023 (for $20 \mathrm{~km}$ ). The coefficients change only slightly in magnitude but their signs and statistical significance remain, indicating the robustness of our results.

Since datasets addressing individual travelling behaviour are rarely publicly available at the localized level for the study area, we resort to the COVID-19 Impact Analysis Platform by the University of Maryland ${ }^{44,45}$ for a national-level exploration. Established for studies on COVID-19's impact, this dataset includes the daily number of trips per person at the county level starting from 1 
Table 4 | Effect of air pollution on solar energy generation in commercial buildings

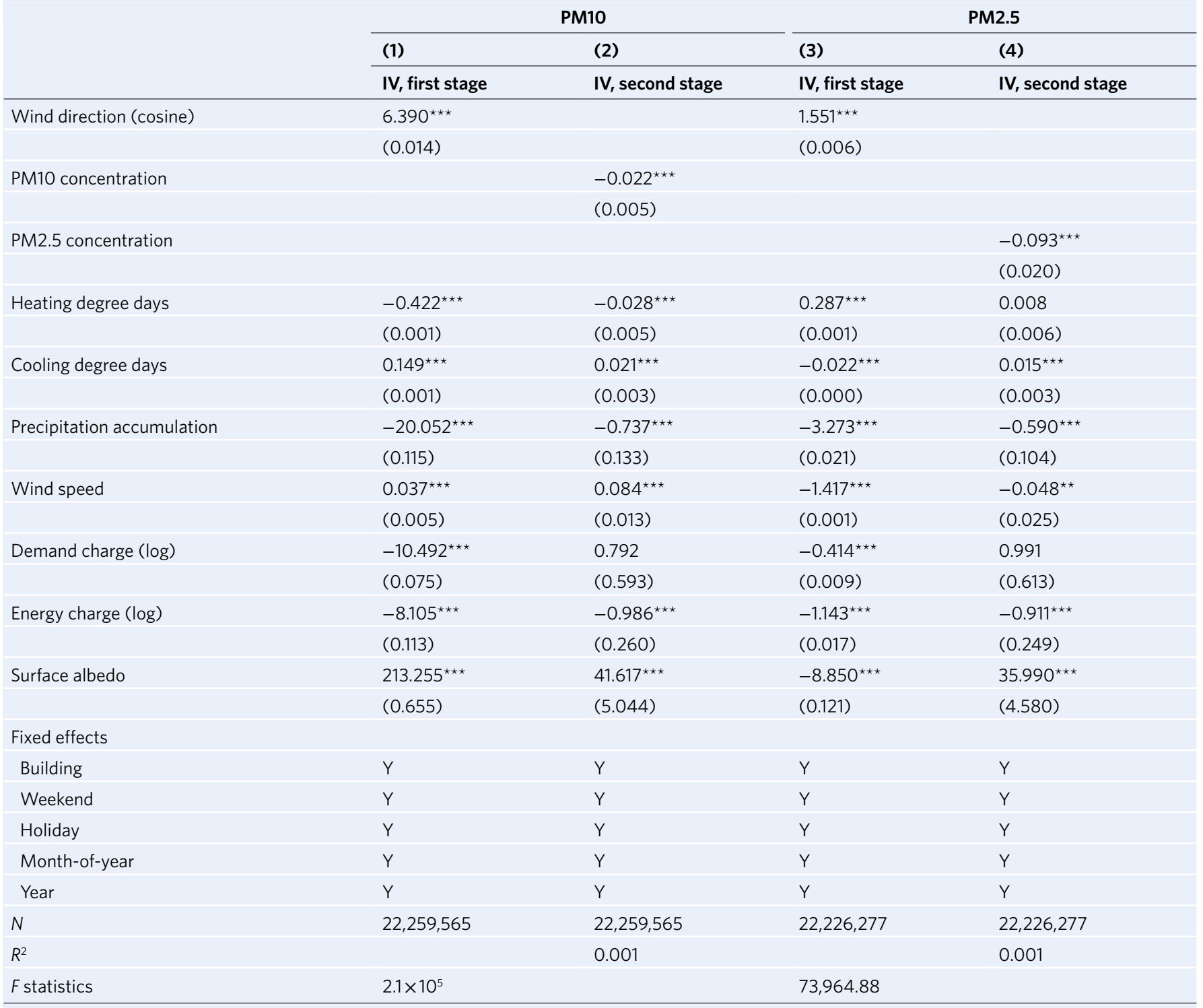

Notes: Standard errors in parentheses are clustered to building unit level. ${ }^{\star} P<0.1,{ }^{\star \star} P<0.05,{ }^{\star \star \star} P<0.01$. N denotes the sample size and $R^{2}$ denotes the goodness-of-fit of the regressions.

January 2020, which is further broken down into work and non-work trips. The information on trips comes from mobile device location data. Since the massive outbreak of COVID-19 in the United States took place no earlier than March, we adopt the records in January and February and match them with the air pollution and climate data from the above sources using a similar method.

Empirical strategies. We first estimate a generalized linear squared model on the panel dataset of residential and commercial units separately with the equation

Elec_Con $_{i t}=\beta_{1}$ Pollution $_{i t}+\mathbf{X}_{i t}+\alpha_{i}+\tau_{y}+\delta_{m}+$ Weekend $_{t}+$ Holiday $_{t}+\varepsilon_{i t}$

where $i$ indexes an individual residential or commercial consumer and $t$ indexes the day of the sample. Elec_Con ${ }_{i t}$ refers to the daily electricity consumption of consumer $i$ on day $t$. Pollution ${ }_{i t}$ is the daily average concentration of either PM10 or PM2.5. $\mathbf{X}_{i t}$ is a vector of control variables, including cooling degree days and heating degree days (estimated using daily average temperature), daily total precipitation, wind speed and electricity price (average daily electricity price for the residential consumers, and demand charge and energy charge for the commercial units). We also control for the concentration of ozone as another major pollutant that affects air quality and thus the outdoor activities of consumers. The variable $\alpha_{i}$ is customer fixed effect, and it controls for the time-invariant attributes of the consumer such as square footage and the number of stories as well as environmental awareness of building occupants. The time fixed effects $\tau_{y}$ and $\delta_{m}$ include the year fixed effect and the month-of-year fixed effect. The time fixed effects capture the time-varying factors across years and seasons, such as economic development and change in local energy policies. Weekend and Holiday are dummy variables for holidays and weekends, respectively. The Holiday dummy is equal to one if the day belongs to the following US federal holidays: New Year's Day, Martin Luther King Jr Day, Presidents' Day, Memorial Day, Independence Day, Labor Day, Columbus Day, Veterans Day, Thanksgiving and Christmas. The $\varepsilon_{i, t}$ is the error term. Standard errors are clustered at the building level. We are interested in $\beta_{1}$, which indicates the electricity use increase per $\mu \mathrm{g} \mathrm{m}^{-3}$ increase of particulate concentration, ceteris paribus.

We analyse how the impact of air pollution differs by different income groups. Using the available data on household characteristics, the sample is divided into three levels of per capita income: low, medium and high. The division, provided by the Pew Research Center, is based on the minimum household income level of different household sizes varying from one to five (US\$24,042/34,000/41,641/48, $083 / 53,759$ for middle income, and US $\$ 72,126 / 102,001 / 124,925 / 144,251 / 161,277$ for upper income in 2014 (ref. ${ }^{46}$ )). Since the household size is recorded as 1.5, 3.5 and 5 persons, we take an average of the two adjacent minimum household income levels for the 1.5- and 3.5-person households.

We test whether and by how much the particulate pollution affects solar energy generation with,

Elec_Solar $_{i t}=\beta_{1}$ Pollution $_{i t}+\mathbf{X}_{i t}+\alpha_{i}+\tau_{y}+\delta_{m}+$ Weekend $_{t}+$ Holiday $_{t}+\varepsilon_{i t}$ 
where Elec_Solar ${ }_{i t}$ refers to the daily electricity generated by solar for consumer $i$ on day $t$, and the other terms are the same as in equation (1). The $\mathbf{X}_{i t}$ is modified to adapt to factors that can affect the power generation of solar panels, including climate factors that can affect the performance of solar power (temperature, precipitation, wind speed and surface albedo) and electricity prices, which can affect the motivation of consumers to actively maintain solar panels in good condition (consumers are encouraged to do so if the price is higher). The distributed-solar consumers in our sample were on a net-metering plan under which they could sell excessive solar electricity at retail electricity prices.

The naïve general least squares (GLS) estimation (results shown in Supplementary Tables 6-9) suffers from endogeneity issues due to reverse causality and missing variables ${ }^{47,48}$. As air pollution changes the behaviour patterns and increases the energy consumption of consumers, the latter can result in more electricity generation and thus pollution emissions. Meanwhile, if consumers spend more time indoors, the demand for vehicle travel may also decrease and lead to reduced emissions from transportation ${ }^{48}$. Omitting such pathways would lead to a biased estimation of the effect of air pollution. Besides, air quality and individual socio-economic activities can be jointly affected by the same factors, such as the local economy and physical environment ${ }^{47}$. Since all such factors cannot be observed in our datasets, these missing variables could bias the estimation.

To address these issues, we resort to using wind direction for an IV estimation. Its validity has been verified by multiple existing air pollution studies ${ }^{47,49,50}$. The idea is that wind direction affects regional air quality as it transports pollutants in specific directions. As the wind direction fluctuates on a daily or even hourly basis, it can convert the study area upwind or downwind of the pollution. Other than this pathway, wind direction (while controlling for wind speed) can hardly affect electricity consumption or solar electricity generation, and thus can meet the exclusive restriction for a valid IV.

We use the daily average cosine of the angle between the prevailing wind direction and the hourly wind direction as our IV following the previous studies ${ }^{47,51}$ with modifications to adapt to our daily-level data. We first plot the distribution of the hourly wind direction of all the climate stations to obtain the prevailing wind direction, which turns out to be $180^{\circ}$. We then calculate the cosine of the angle between each hourly wind direction observation and this prevailing direction, and finally obtain the daily average for each climate station, which matches with different zip code zones. In this way, we can conduct the first-stage regression before running equation (1) or (2) as

Pollution $_{i t}=\gamma_{1}$ Wind_dir $_{i t}+\mathbf{X}_{i t}+\alpha_{i}+\tau_{y}+\delta_{m}+$ Weekend $_{t}+$ Holiday $_{t}+e_{i t}$

where Wind_dir ${ }_{i t}$ indicates the daily wind direction variable, $e_{i t}$ is the error term and other terms are the same as in equations (1) and (2). The coefficient $\gamma_{1}$, after we run the first-stage model, is statistically significant with an $F$ value larger than ten, implying that the IV is relevant and strong. We then use the predicted values of pollution from equation (3) in the second-stage model when we run equation (1) or (2).

It should be noted that the maximum value of the electricity consumption of the commercial buildings in our sample is extraordinarily large (Supplementary Table 3). However, there is no way for us to rule out the possibility that this value is reasonable given the decent variation of daily electricity consumption in the commercial buildings that this value belongs to. Therefore, we keep these potential outliers for the main analysis but also rerun the regressions, dropping commercial buildings with a maximum daily electricity consumption over $500 \mathrm{kWh}$ and $1,000 \mathrm{kWh}$. The results provided in Supplementary Tables 10 and 11 show that our key results remain robust after the change. Also, about $10 \%$ of the buildings have a constant daily electricity consumption of zero in the raw data. We regard them as shut-down buildings and remove them from our sample.

We further test how air pollution affects residential and commercial electricity consumption at the hourly level. The identification is similar to equation (1) but using the matched hourly data of electricity use and air quality (lagged for one hour). The electricity consumption and solar electricity generation of one particular hour will not influence the air quality of the previous hour, and thus there is no reverse causality issue. In addition, such an immediate hourly reaction of building energy use will not lead to an immediate change (within the same hour) in local PM pollution levels for the following reason. The hourly change in building electricity consumption leads to an hourly change in electricity generated at power plants. The coal-fired power plants surrounding the Phoenix metropolitan area are all located at least 100 miles away. This implies that the transmission of the PM pollution from these power plants to Phoenix will take time (considering that the average wind speed in Arizona cities is less than 23 miles per hour and the average wind speed in our sample is $2.66 \mathrm{~m} \mathrm{~s}^{-1}$ or 6 miles per hour), and thus will not influence the local PM pollution within an hour. The notable hourly variation in local PM pollution (such as in morning hours and late afternoon hours) in Arizona mostly comes from other sources such as motor vehicles and road dust, instead of from power plants, based on the study by Clements et al. (ref. ${ }^{52}$ ). As a result, the hourly change in building energy consumption will not alter local PM pollution in the Phoenix metropolitan area immediately.
To examine whether individuals stay at home instead of commuting to work on polluted days, we conduct a regression analysis on personal trips with,

$$
\operatorname{Trip}_{j t}=\beta_{1} \text { Pollution }_{j t}+\mathbf{X}_{j t}+\pi_{j}+\delta_{m}+\text { dow }_{t}+\varepsilon_{j t}
$$

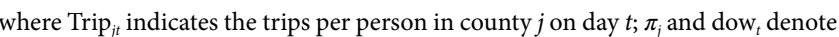
the county and day-of-week fixed effects; and the other terms are similar to those in equations (1) and (2) but at the county level. On the basis of regressions using the total trips, we further test the effect of pollution concentration on the work and non-work trips. Due to a similar source of endogeneity, we are instrumenting the pollution using the wind direction with,

$$
\text { Pollution }_{j t}=\gamma_{1} \text { Wind_dir }_{j t}+\mathbf{X}_{j t}+\pi_{j}+\delta_{m}+\text { dow }_{t}+e_{j t}
$$

where Wind_dir ${ }_{j t}$ indicates the daily wind direction variable for county $j$ on day $t$ and the other terms are the same as in equation (4). We calculate the daily average cosine of the angle between the prevailing wind direction and the hourly wind direction as our IV in a similar way to that described above. The prevailing wind direction is retrieved from the median of the wind angle of each county during the study period.

\section{Data availability}

Records of air quality and hourly wind direction were retrieved from pre-generated data files of the United States Environmental Protection Agency at https://aqs. epa.gov/aqsweb/airdata/download_files.html. Climate factors were obtained from Global Surface Summary of the Day at ftp://ftp.ncdc.noaa.gov/pub/data/ gsod/. The solar irradiance data from the National Renewable Energy Laboratory's National Solar Radiation Database is at https://maps.nrel.gov/nsrdb-viewer. The high-frequency electricity data are from the Salt River Project. As they are restricted by a non-disclosure agreement, they are available from the authors upon reasonable request and with permission from the SRP. The county-level trip data are available upon request from the COVID-19 Impact Analysis Platform of the University of Maryland at https://data.covid.umd.edu/about/index.html. Source data are provided with this paper.

\section{Code availability}

All data and models are processed in Stata 14.0. The figures are produced in R studio (based on R 3.6.1). All custom code is available on GitHub at https://github.com/hepannju/ Increase-in-domestic-electricity-consumption-from-particulate-air-pollution.

Received: 23 March 2020; Accepted: 23 August 2020; Published online: 21 September 2020

\section{References}

1. Graff Zivin, J. \& Neidell, M. The impact of pollution on worker productivity. Amer. Econ. Rev. 102, 3652-3673 (2012).

2. Chang, T., Graff Zivin, J., Gross, T. \& Neidell, M. Particulate pollution and the productivity of pear packers. Am. Econ. J. Econ. Policy 8, 141-169 (2016)

3. Levinson, A. Valuing public goods using happiness data: the case of air quality. J. Public Econ. 96, 869-880 (2012).

4. Chen, X. Smog, cognition and real-world decision-making. Int. J. Health Policy Manag. 8, 76-80 (2019).

5. Zhang, X., Chen, X. \& Zhang, X. The impact of exposure to air pollution on cognitive performance. Proc. Natl Acad. Sci. USA 115, 9193-9197 (2018).

6. de Marco, A. et al. Impacts of air pollution on human and ecosystem health, and implications for the National Emission Ceilings Directive: insights from Italy. Environ. Int. 125, 320-333 (2019).

7. Chay, K. \& Greenstone, M. Does air quality matter? Evidence from the housing market. J. Polit. Economy 113, 376-424 (2005).

8. Goulder, L. \& Schein, A. Carbon Taxes Vs. Cap and Trade: a Critical Review (National Bureau of Economic Research, 2013); https://doi.org/10.3386/ w19338

9. Sun, C., Kahn, M. E. \& Zheng, S. Self-protection investment exacerbates air pollution exposure inequality in urban China. Ecol. Econ. 131, 468-474 (2017).

10. Zivin Graff, J. \& Neidell, M. Days of haze: environmental information disclosure and intertemporal avoidance behavior. J. Environ. Econ. Manage. 58, 119-128 (2009).

11. Ward, A. L. S. \& Beatty, T. K. Who responds to air quality alerts? Environ. Resource Econ. 65, 487-511 (2016).

12. Zhang, J. \& Mu, Q. Air pollution and defensive expenditures: evidence from particulate-filtering facemasks. J. Environ. Econ. Manage. 92, 517-536 (2018).

13. Chen, S., Oliva, P. \& Zhang, P. The Effect of Air Pollution on Migration: Evidence from China (National Bureau of Economic Research, 2017); https:// doi.org/10.3386/w24036

14. Graff Zivin, J. \& Neidell, M. Environment, health, and human capital. J. Econ Lit. 51, 689-730 (2013). 
15. Sexton, A. L. Health and Environmental Implications of Americans' Time Use Responses to External Stimuli: Essays on Air-Quality Alerts and Daylight Savings Time. PhD thesis, Univ. of Minnesota (2012).

16. Tong, Z., Chen, Y., Malkawi, A., Liu, Z. \& Freeman, R. B. Energy saving potential of natural ventilation in China: the impact of ambient air pollution. Appl. Energy 179, 660-668 (2016).

17. Cao, X., Dai, X. \& Liu, J. Building energy-consumption status worldwide and the state-of-the-art technologies for zero-energy buildings during the past decade. Energy Build. 128, 198-213 (2016).

18. Hiller, C. Factors influencing residents' energy use-a study of energy-related behaviour in 57 Swedish homes. Energy Build. 87, 243-252 (2015).

19. de Nazelle, A. et al. Improving estimates of air pollution exposure through ubiquitous sensing technologies. Environ. Pollut. 176, 92-99 (2013).

20. Kumar, P. et al. Indoor air quality and energy management through real-time sensing in commercial buildings. Energy Build. 111, 145-153 (2016).

21. Streets, D. G., Wu, Y. \& Chin, M. Two-decadal aerosol trends as a likely explanation of the global dimming/brightening transition. Geophys. Res. Lett. https://doi.org/10.1029/2006GL026471 (2006).

22. Sweerts, B. et al. Estimation of losses in solar energy production from air pollution in China since 1960 using surface radiation data. Nat. Energy 4, 657-663 (2019).

23. Li, X., Wagner, F., Peng, W., Yang, J. \& Mauzerall, D. L. Reduction of solar photovoltaic resources due to air pollution in China. Proc. Natl Acad. Sci. USA 114, 11867-11872 (2017).

24. Tessum, C. W. et al. Inequity in consumption of goods and services adds to racial-ethnic disparities in air pollution exposure. Proc. Natl Acad. Sci. USA 116, 6001-6006 (2019)

25. Nair, G., Gustavsson, L. \& Mahapatra, K. Factors influencing energy efficiency investments in existing Swedish residential buildings. Energy Policy 38, 2956-2963 (2010).

26. Liang, J., Liu, P., Qiu, Y., Wang, Y. D. \& Xing, B. Time-of-use electricity pricing and residential low-carbon energy technology adoption. Energy J. 41, 1944-9089 (2020).

27. White, L. V. \& Sintov, N. D. Health and financial impacts of demand-side response measures differ across sociodemographic groups. Nat. Energy 5, 50-60 (2020).

28. Phoenix now the 5th-largest city in the US, census says. Fox News https:// www.foxnews.com/us/phoenix-now-the-5th-largest-city-in-the-us-census-says (2017)

29. Ridlington, E. \& Leavit, C. Trouble in the Air-Millions of Americans Breathe Polluted Air (Environment America Research \& Policy Center, 2018); https:// environmentarizonacenter.org/sites/environment/files/reports/Trouble\%20 in\%20the\%20Air\%20vAZ.pdf

30. Li, Y., Pizer, W. A. \& Wu, L. Climate change and residential electricity consumption in the Yangtze River Delta, China. Proc. Natl Acad. Sci. USA 116, 472-477 (2019)

31. Reames, T. G. Targeting energy justice: exploring spatial, racial/ethnic and socioeconomic disparities in urban residential heating energy efficiency. Energy Policy 97, 549-558 (2016).

32. Bednar, D. J., Reames, T. G. \& Keoleian, G. A. The intersection of energy and justice: modeling the spatial, racial/ethnic and socioeconomic patterns of urban residential heating consumption and efficiency in Detroit, Michigan. Energy Build. 143, 25-34 (2017).

33. Ng, L. C., Musser, A., Persily, A. K. \& Emmerich, S. J. Indoor air quality analyses of commercial reference buildings. Build. Environ. 58, 179-187 (2012)

34. Arceo, E., Hanna, R. \& Oliva, P. Does the effect of pollution on infant mortality differ between developing and developed countries? Evidence from Mexico City. Econ. J. 126, 257-280 (2016).

35. Freeman, R., Liang, W., Song, R. \& Timmins, C. Willingness to pay for clean air in China. J. Environ. Econ. Manage. 94, 188-216 (2019).

36. Janke, K. Air pollution, avoidance behaviour and children's respiratory health: evidence from England. J. Health Econ. 38, 23-42 (2014).

37. Tribby, C. P., Miller, H. J., Song, Y. \& Smith, K. R. Do air quality alerts reduce traffic? An analysis of traffic data from the Salt Lake City metropolitan area, Utah, USA. Transp. Policy 30, 173-185 (2013).

38. Noonan, D. S. Smoggy with a chance of altruism: the effects of ozone alerts on outdoor recreation and driving in Atlanta. Policy Stud. J. 42, 122-145 (2014)
39. Air Quality Pre-generated Data Files (United States Environmental Protection Agency, 2013-2018); https://aqs.epa.gov/aqsweb/airdata/download_files. html\#Raw

40. Global Summary of the Day (National Centers for Environmental Information, 2013-2018); ftp://ftp.ncdc.noaa.gov/pub/data/gsod/

41. National Solar Radiation Database (National Renewable Energy Laboratory, accessed 7 January 2019); https://maps.nrel.gov/nsrdb-viewer

42. Zhang, P., Deschenes, O., Meng, K. \& Zhang, J. Temperature effects on productivity and factor reallocation: evidence from a half million Chinese manufacturing plants. J. Environ. Econ. Manage. 88, 1-17 (2018).

43. Deschênes, O. \& Greenstone, M. Climate change, mortality, and adaptation evidence from annual fluctuations in weather in the US. Am. Econ. J. Appl. Econ. 3, 152-185 (2011)

44. Zhang, L. et al. An interactive COVID-19 mobility impact and social distancing analysis platform. Preprint at https://www.medrxiv.org/content/10. $1101 / 2020.04 .29 .20085472 \mathrm{vl}(2020)$

45. University of Maryland COVID-19 Impact Analysis Platform (Maryland Transportation Institute, 2020); https://data.covid.umd.edu

46. Who Is 'Middle Income' and 'Upper Income' in 2014? (Pew Research Center, 2016); https://www.pewsocialtrends.org/2016/05/11/americas-shrinking-middle-class-a-close-look-at-changes-within-metropolitan-areas/ st_2016-05-12_middle-class-geo-03/

47. Barwick, P. J., Li, S., Deyu, R. \& Zahur, N. B. Air Pollution, Health Spending and Willingness to Pay for Clean Air in China (Semantic Scholar, 2018); https://pdfs.semanticscholar.org/7819/8c81716d00638acd74fadf1c12a19202d 7c1.pdf

48. Sager, L. Estimating the effect of air pollution on road safety using atmospheric temperature inversions. J. Environ. Econ. Manage. 98, 102250 (2019).

49. Deryugina, T., Heutel, G., Miller, N. H., Molitor, D. \& Reif, J. The mortality and medical costs of air pollution: evidence from changes in wind direction. Amer. Econ. Rev. 109, 4178-4219 (2019).

50. Zheng, S., Cao, J., Kahn, M. E. \& Sun, C. Real estate valuation and cross-boundary air pollution externalities: evidence from Chinese cities. J. Real Estate Finance Econ. 48, 398-414 (2014).

51. Anderson, M. L. As the wind blows: the effects of long-term exposure to air pollution on mortality. J. Eur. Econ. Assoc. 18, jvz051 (2019).

52. Clements, A. L. et al. Source identification of coarse particles in the Desert Southwest, USA using Positive Matrix Factorization. AtmosPollut. Res. 8, 873-884 (2017)

\section{Acknowledgements}

Funding for this research was provided by the National Science Foundation under grant no. 1757329. We thank J.H. Scofield, C. Canfield, Y. Li, H. Zhang and the seminar participants at the Center for Global Sustainability of University of Maryland, Division of Resource Economics and Management of University of West Virginia, and the Institute of Energy, Environment and Economy of Tsinghua University for their helpful comments during the preparation of this paper.

\section{Author contributions}

All the authors conceived the paper and designed the research. P.H., J.L. and Y.Q. designed the analysis methods, performed the analyses and wrote and revised the paper B.X. processed the data. Q.L. reviewed several draughts and made revisions.

\section{Competing interests}

The authors declare no competing interests.

\section{Additional information}

Supplementary information is available for this paper at https://doi.org/10.1038/ s41560-020-00699-0.

Correspondence and requests for materials should be addressed to P.H. or Y.Q. Reprints and permissions information is available at www.nature.com/reprints. Publisher's note Springer Nature remains neutral with regard to jurisdictional claims in published maps and institutional affiliations.

(c) The Author(s), under exclusive licence to Springer Nature Limited 2020 